\title{
The Impacts of Transportation, Environmental Health and Medical Systems on the Urban Human Settlement Environment at the Early Stage of Tibet's Peaceful Liberation
}

\author{
Jie Li \\ Sichuan University, China
}

Keywords: human settlement environment; Tibet; urbanization

\begin{abstract}
Due to special geographical and political factors, cities in Tibet developed pretty slowly before 1950s. The living environment was bad, while the improvement of human settlements was neglected for a long period time. After the peaceful liberation, the Central Committee began to strengthen city construction of Tibet in all aspects. From three aspects of transportation, environmental sanitation and medical treatment, this paper describes the status of urban development in Tibet before 80s, and discusses the positive impacts of living environment improvement in various cities and regions of Tibet. The construction of good living environment plays a vital role in the development of cities in Tibet.
\end{abstract}

\section{Introduction}

Situated in the Qinghai-Tibet Plateau, Tibet is located in the southwest border areas of China. Covers an area of 1.2 million square kilometers and with the average altitude of more than 4000 meters, Tibet is known as the roof of the world. Because of its special geographical location, the climate of Tibet is cold, dry, complex and changeable; ecological environments here are extremely fragile. "In Tibet, the lands are uneven; in low areas it is hot, while in high places it is cold. The weather changes constantly in mountains." [1] The extreme climate led to harsh living environment of Tibet. The problem of urban human settlement environment was rarely noticed before 1950s.

The Japanese Buddhist scholar Kawaguchi Ekai visited Tibet from 1897 to 1903, and recorded the living environment of Lhasa. "There is a deep ditch in the center of the city, which is the toilet for women and travelers, and filled with feces. The smell is not so heavy in winter, but in summer it is horrible. If it rains, muddy water and droppings flow all over the street. ... There are many dogs which can eat dung in Lhasa, but dogs choose fresh dung to eat. The old ones are left behind. Moreover, there are wells beside these dung trenches, and people drink well water. The hygienic condition here is terrible. "[2] It can be seen that the urban environment in Lhasa was awful at that time. Since the establishment of Tibetan regime in ancient China, Lhasa remained as the political center of Tibet for long time. Its geographical environment was superior while its development was fast, but the environmental health status was still terrible; not to mention other cities and regions in Tibet.

In 1950s, Tibet experienced the peaceful liberation and democratic reform. The corrupt serf system was overthrown; Tibet returned to the embrace of motherland. At the same time, the Central Committee of the Communist Party of China began to carry out various construction projects in Tibet, in which the construction of transportation, environmental hygiene and medical systems were closely related to the construction of human living environment. The transportation system is subordinate to the supporting subsystem of human settlement environment. [3] Urban environmental sanitation and medical systems are closely related to the quality of human settlement environment. [4] This paper will discuss these aspects in following sections, and analyze their impacts on urban human settlements of Tibet.

\section{Construction of Transportation System}

Communication and transportation facilities are essential infrastructure in human life, which can 
greatly facilitate the flow of people and goods. Transportation is particularly important for Tibet due to its severe geographical environments. In the past, road traffic in Tibet was inconvenient; the roads were "full of stones, and extremely difficult and dangerous for pedestrians and horses". [5] People needed to travel or transport goods by yaks, mules and horses. The journey usually took a long time; many roads were blocked by rain or snow for most of the year, which made the journey even harder. For instance, for the more than 4000 mile journey from Chengdu to Lhasa, it usually took more than a year. [6] Backward traffic conditions also hindered the development of Tibet and blocked the economic, cultural, personnel and material exchanges between Tibet and mainland.

After the peaceful liberation of Tibet in 50s, the state began to construct road traffic systems in Tibet. "From 1950 to 1951, the Central Committee instructed the Chinese People's Liberation Army to enter Tibet, and begin to explore and construct Kang Tibet highway and the Qinghai Tibet highway while marching." [6] At the same time, "a number of engineering and technical personnel, as well as migrant workers were transferred from mainland and neighboring provinces to Tibet to build Qinghai Tibet and Sichuan Tibet (Kang Tibet) highways ". [7] The state invested a great deal of manpower, material and financial resources to carry out the construction of the Qinghai Tibet and the Sichuan Tibet highways. Among them, there were more than 110 thousand people, including PLA, engineering and technical personnel, as well as migrant workers from all ethnic groups, who participated in the construction of Sichuan Tibet highway. [8] Through the joint efforts of people from all ethnic groups, Sichuan Tibet and Kang Tibet highways officially opened traffic in December 25, 1954.

Sichuan Tibet highway and Qinghai Tibet highway strengthen the connection between Tibet and the mainland of China. Exchanges of all aspects become more frequent afterwards. Without highways, it takes about one year from Lhasa to Chengdu; with the help of highways, the same journey takes only a few days. The exchanges of personnel and materials are greatly facilitated. These two lines not only connect Tibet and other inland provinces (Qinghai and Sichuan), but also connect different towns and cities inside Tibet. The Sichuan Tibet highway passes through Chengdu, Ya'an, Kangding and Xinduqiao, and then divides into two lines of north and south. The north line passes through Ganzi, Dege, Jiangda, Changdu, Dingqing, Naqu, Lhasa and other cities; the south line passes through Yajiang, Litang, Batang, Mangkang, Bangda, Bomi, Linzhi, Gongbujiangda, Lhasa and other places. Traffic among cities and towns inside and outside the Tibet Autonomous Region become more convenient. The two highways also "get through the main line of national road which connects Yunnan, Xinjiang and Tibet, and initially establish the modern transportation system in Tibet together with provincial and county roads which are built afterwards."

The road traffic mileage in the autonomous region was 1988 kilometers in 1954, 14721 kilometers in 1965 and 21511 kilometers in 1980. [9] The passenger traffic volume was 63 thousand in 1959, 93 thousand in 1965 and 354.8 thousand in 1985. [10] It can be seen that the road construction in Tibet developed steadily and rapidly from the peaceful liberation to 1980s. The transportation system is subordinate to the supporting subsystem of living environment system. [3] The convenience of traffic is a key factor which can measure the quality of living environment. The establishment of a modern transportation system in Tibet Autonomous Region makes the communication between different settlements more convenient; the quantity and frequency of travelers in every area of Tibet increased rapidly; the quality of urban settlements was also improved.

\section{Construction of Environmental Sanitation System}

Urban environmental sanitation is an important part in human living environment construction. After the peaceful liberation of Tibet in 1950s, under the leadership of People's Liberation Army, the health protection project was carried out mainly in cities and towns of Tibet; the project included tasks of eliminating garbage dumps, dredging drainage ditches, repairing pavements and constructing public toilets; it elementarily changed the dirty, disorderly and bad situation of cities and towns. [11] In 1953, Sanitation and Hygiene Committees were established in Lhasa and Dengqing County. They were the earliest mass organization on health protection in Tibet. The Committee mobilized and organized citizens to carry out various health activities. After that, Patriotic Health Movement 
Committees were set up in all parts of Tibet. [12] The environmental sanitation project was carried out initially and formally.

After the democratic reform in 1959, environmental sanitation works gradually stepped on the track in all parts of Tibet. During 1960s to 1970s, "Lhasa, Changdu as well as other cities and towns set up urban cleaning teams, which were responsible for the cleaning of garbage and other works." [11] Environmental sanitation works became more effective and regular with remarkable effects. In 1974, in Chengguan District of Lhasa, "16 new public toilets were set up; 79 existing public toilets were cleared; 4 refuse dumps which had piled up throughout years were transported; more than 15000 baskets of fertilizer were accumulated; 30 drinking water wells were cleaned and equipped with well covers." [11] In addition, relevant departments also publicized the knowledge on environment and health protection through newspapers, radio and other media, and cultivated citizens' healthy living habits like bathing, hairdressing, dressing, as well as human and animal separating. The establishment of environmental sanitation department and the development of all kinds of health education activities effectively improved the living environment of cities in Tibet.

\section{Construction of Medical System}

For the construction of medical system, in early 50s, the state dispatched medical teams to serve people in Tibet. "In 1951, the northwest medical team, southwest medical team and Panchen Lama medical team went to Tibet with the army." [12] In 1953, the Central Committee organized 125 experts from internal medicine department, surgery department and gynecology department to form a health team and go to Tibet. [13] In addition, hospitals and clinics were established in Tibet. In 1952, the first comprehensive medical hospital in Tibet, Changdu People's Hospital, was established. In 1956, "18 health centers were established in Tibet; free medical treatment was provided for Tibetans. A large number of medical teams were sent to rural and pastoral areas to cure diseases." [13] From 1973 to 1983, 5 batches of medical teams, nearly 2000 medical personnel were sent to Tibet. [14] It can be seen that the state provided a great deal of assistance to the construction of medical system in the Tibet Autonomous Region.

In old Tibet, under the control of the long-term state and religion unification system, medical and health facilities were almost zero. The mortality rate, especially the infant mortality rate was very high; limited resources were basically controlled by aristocrats and temples. [15] After the peaceful liberation, the large-scale medical aid changed the basic medical and health situations of Tibet. The health of the masses was guaranteed; infectious diseases such as influenza, smallpox, cholera and measles were effectively controlled. [11] Life expectancy was also prolonged, which illustrated the improvement of living environment quality. In addition, various forms of health knowledge publicity activities, such as distributing leaflets and newspapers to citizens to publicize infectious disease prevention, and the establishment of bulletin boards in crowded places like the Cultural Palace of Lhasa and trade companies in 70s, produced good effects.

From above, it can be seen that the urban health and medical environment in Tibet transformed after the peaceful liberation; health environment in cities was effectively improved; the quality of medical work in cities, towns and countries was upgraded; urban health environment and medical environment already participated in the evaluation of human living environment quality. [16] Human settlements in various cities of Tibet were greatly improved. The process of urbanization was accelerating, while the number of urban residents was increasing. Cities became more acceptable for outsiders. These changes laid a good foundation for the development of cities in Tibet and the construction of human settlement environment in the future.

\section{Conclusion}

This paper mainly discusses the development and construction of transportation system, urban environmental sanitation system and medical system in Tibet in the early period of Tibet's Peaceful Liberation, as well as their impacts on the living environment of various cities and towns. It can be seen that before 1980s, the construction of these three aspects had made considerable progress. In 
transportation aspect, the Sichuan Tibet highway and Qinghai Tibet highway opened to traffic, then provincial roads as well as county and township roads were built in that area. They greatly facilitated the communication among cities and towns inside and outside Tibet. At the same time, a traffic management department was set up; the modern transportation system was established. Traffic in Tibet became much more convenient.

For urban environmental sanitation, from the beginning of 1950s, various urban sanitary and cleaning projects were carried out; diversified specialized environmental sanitation organizations and institutions were set up. The urban environmental hygiene work became regular and effective. At the same time, the environmental hygiene consciousness of the masses was cultivated. The situation of urban environmental sanitation was greatly improved compared with that of 1950s. For medical system, after the peaceful liberation of Tibet, the state sent medical teams to Tibet, and established hospitals in various places to provide medical services for Tibetan residents. All kinds of diseases were effectively controlled after these measures, while the medical work was gradually improved.

The three aspects of transportation system, urban environmental sanitation system and medical system are closely related to the evaluation of human living environment quality. Development and progress in these three aspects preliminarily improved the living environment of cities in Tibet. Urban population in Tibet was 108.7 thousand in 1965, 176.5 thousand in 1975 and 237.7 thousand in 1980. [7] The number of urban population increased and the level of urbanization lifted before 1980s. These data shows the gradually improving status of urban living environment, which can attract more outsiders to live in Tibet. After the reform and opening up in 1980s, with the development of economic construction, an increasingly number of workers and businessmen moved to Tibet. At the same time, issues about urban infrastructure construction, urban environmental protection and other aspects related to urban human living environment has attracted the attention from various departments of the Autonomous Region. The quality of human living environment in cities of Tibet would be continuously improved.

\section{References}

[1] Y.Q. Jiao, Tibet Chronicles, Wen Hai Publishing House, Taipei, 1966.

[2] K. Ekai, S.Q. Sun (Trans.), Tibet Secret Travel, Xinjiang People's Publishing House, Urumchi, 1998.

[3] L.Y. Wu, Introduction to Sciences of Human Settlements, China Architecture \& Building Press, Beijing, 2001.

[4] Ministry of Housing and Urban-Rural Development of People's Republic of China, Evaluation Index System of China Human Settlements and Environment Award, 2016.

[5] M.C. Bai, Summary of Tibet's Whole Story, Construction Library, Peiping, 1930.

[6] Group of Literature, Department of Transportation of Tibet Autonomous Region, Archives in Commemoration of the 30th Anniversary of Sichuan-Tibet Highway and Qinghai-Tibet Highway Open Traffic, The Tibet People's Publishing House, Lhasa, 1984.

[7] Chorography Compilation Committee of Tibet Autonomous Region, Chorography of Tibet Autonomous Region: Population Volume, chief editors' ed., 2006.

[8]https://baike.baidu.com/item/\%E5\%B7\%9D\%E8\%97\%8F\%E5\%85\%AC\%E8\%B7\%AF/574943 ?fr=aladdin.

[9] Statistics Bureau of Tibet Autonomous Region: Tibet Statistical Yearbook of 2010, China Statistics Press, Beijing, 2010.

[10] Statistics Bureau of Tibet Autonomous Region: Tibet Statistical Yearbook of 1994, China Statistics Press, Beijing, 1994.

[11] Chorography Compilation Committee of Tibet Autonomous Region, Chorography of Tibet 
Autonomous Region: Hygiene Volume, Chinese Tibetan Publishing House, Beijing, 2011.

[12] Health Department, Tibet Autonomous Region, Health Conditions of Tibet in Forty Years, Sichuan Science and Technology Press, Chengdu, 1991.

[13] Z.M. Xu, Review on the project of aiding Tibet of Central Committee of the Communist Party of China, J. Journal of University of Jinan (Social Science Edition). 3 (2012).

[14] The Compiling Group of the General Situation of Tibet Autonomous Region, General Situation of Tibet Autonomous Region, The Ethnic Publishing House, Beijing, 2009.

[15] X.Y. He, Research on the Practice of Ethnic Policies in Tibet since the Peaceful Liberation, Social Sciences Academic Press (CHINA), Beijing, 2015.

[16] X.M. Li, B. Jiang, Evaluating the sustainable development of urban human settlements environment: Taking Dalian as an example, J. China Population, Resources and Environment. 6 (2002). 